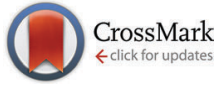

Cite this: Phys. Chem. Chem. Phys., 2015, 17, 23195

Received 6th July 2015 Accepted 6th August 2015

DOI: $10.1039 / c 5 c p 03914 b$

www.rsc.org/pccp

\title{
Coordination structure and charge transfer in microsolvated transition metal hydroxide clusters $[\mathrm{MOH}]^{+}\left(\mathrm{H}_{2} \mathrm{O}\right)_{1-4} \dagger$
}

\author{
Brett M. Marsh, Jonathan M. Voss, Jia Zhou and Etienne Garand*
}

\begin{abstract}
Infrared vibrational predissociation spectra of transition metal hydroxide clusters, $[\mathrm{MOH}]^{+}\left(\mathrm{H}_{2} \mathrm{O}\right)_{1-4} \cdot \mathrm{D}_{2}$ with $\mathrm{M}=\mathrm{Mn}, \mathrm{Fe}, \mathrm{Co}, \mathrm{Ni}, \mathrm{Cu}$, and $\mathrm{Zn}$, are presented and analyzed with the aid of density functional theory calculations. For the $[\mathrm{MnOH}]^{+},[\mathrm{FeOH}]^{+},[\mathrm{CoOH}]^{+}$and $[\mathrm{ZnOH}]^{+}$species, we find that the first coordination shell contains three water molecules and the four ligands are arranged in a distorted tetrahedral geometry. $[\mathrm{CuOH}]^{+}$can have either two or three water molecules in the first shell arranged in a planar arrangement, while $[\mathrm{NiOH}]^{+}$has an octahedral ligand geometry with the first shell likely closed with five water molecules. Upon closure of the first coordination shell, characteristic stretch frequencies of hydrogen-bonded $\mathrm{OH}$ in the $2500-3500 \mathrm{~cm}^{-1}$ region are used to pinpoint the location of the water molecule in the second shell. The relative energetics of different binding sites are found to be metal dependent, dictated by the first-shell coordination geometry and the charge transfer between the hydroxide and the metal center. Finally, the frequency of the hydroxide stretch is found to be sensitive to the vibrational Stark shift induced by the charged metal center, as observed previously for the smaller $[\mathrm{MOH}]^{+}\left(\mathrm{H}_{2} \mathrm{O}\right)$ species. Increasing solvation modulates this frequency by reducing the extent of the charge transfer while elongating the $\mathrm{M}-\mathrm{OH}$ bond.
\end{abstract}

\section{Introduction}

Interactions between a metal center and its ligands are important for the stability of the complex as well as its functionality. While such interactions can be modified by functional groups on the ligand, it can be further altered by the presence of solvent molecules. For example, the extent of charge transfer between a metal center and a ligand group can be influenced by interactions with nearby polar solvents, ${ }^{1-4}$ and the structural arrangement of the ligand groups can also vary depending on local solvation environment. Two recent studies highlight the intricacies present in such solvent-driven changes in metalligand interactions for the simple case of $[\mathrm{MOH}]^{+}$complexes. In a vibrational predissociation study by Johnson et al., ${ }^{5}$ they found that the hydroxide frequency redshifts with increasing solvation in the $[\mathrm{MgOH}]^{+}\left(\mathrm{H}_{2} \mathrm{O}\right)_{1-5}$ and $[\mathrm{CaOH}]^{+}\left(\mathrm{H}_{2} \mathrm{O}\right)_{1-5}$ clusters. On the other hand, the same hydroxide stretch blueshifts with increasing solvation in the $[\mathrm{CuOH}]^{+}\left(\mathrm{H}_{2} \mathrm{O}\right)_{1-3}$ clusters. ${ }^{6}$ Furthermore, these complexes have rather different solvation structures, distinctive from each other when surrounded by three or more water molecules.

Department of Chemistry, University of Wisconsin-Madison, 1101 University Avenue, Madison, WI 53706, USA. E-mail: egarand@chem.wisc.edu $\dagger$ Electronic supplementary information (ESI) available. See DOI: 10.1039/ c5
In an effort to understand the differences manifested in these prototypical ion pair metal complexes, we recently probed the charge transfer between the metal and hydroxide ligand in the small $[\mathrm{MOH}]^{+}\left(\mathrm{H}_{2} \mathrm{O}\right)$ complexes for the $\mathrm{Mn}-\mathrm{Zn}$ series. $^{7}$ Interestingly, we found that the degree of charge transfer is mainly dictated by the 2 nd ionization potential of the transition metal, although such a trend does not hold for the alkali earth metals. Additionally, the vibrational frequency of the hydroxide ligand demonstrates a high sensitivity to the local charge environment, varying by $>150 \mathrm{~cm}^{-1}$ depending on the electric field induced by the metal center. This dramatic vibrational Stark shift provides a well behaved correlation between the observed hydroxide frequency and the extent of charge transfer. This trend holds true for $[\mathrm{MgOH}]^{+}$and $[\mathrm{CaOH}]^{+}$as well, allowing the hydroxide frequency to serve as an effective in situ probe of charge transfer. Therefore, the observed opposing trends in the hydroxide stretch for $[\mathrm{MgOH}]^{+}\left(\mathrm{H}_{2} \mathrm{O}\right)_{1-5},[\mathrm{CaOH}]^{+}\left(\mathrm{H}_{2} \mathrm{O}\right)_{1-5}$, and $[\mathrm{CuOH}]^{+}\left(\mathrm{H}_{2} \mathrm{O}\right)_{1-3}$ clusters are likely reflecting different solvent-driven changes in the metal-ligand charge transfer.

Another open question is how the presence of a charged ligand affects the solvation structure of the metal complex. There are only a few studies on the stepwise solvation of ion pairs, ${ }^{3,5-8}$ but many reports have focused on the molecular-level interactions controlling solvation of isolated alkali and transition metal ions. Gas-phase studies of these singly and doubly 
charged clusters have proven an essential tool for understanding fundamental solvation processes. Specifically, coordination numbers and sequential binding energies of water molecules have been previously determined by collision-induced-dissociation mass spectrometry (CID-MS) for the singly charged transition metals $\mathrm{Ti}-\mathrm{Cu}^{9}$ as well as for $\mathrm{Ca}^{2+}, \mathrm{Mg}^{2+}$, and $\mathrm{Fe}^{2+}$, and $\mathrm{Zn}^{2+} \cdot{ }^{10-14}$ Additionally, structures of hydrated singly and doubly charged alkali and transition metal clusters have been very well characterized by photodissociation spectroscopy. ${ }^{15-26}$

Building on these results of solvated metal ions, we extend our study of the $[\mathrm{MOH}]^{+}$species to larger clusters to probe the effect of solvation on the $\mathrm{M}-\mathrm{OH}$ charge transfer as well as to determine how the coordination sphere is influenced by the charged hydroxide ligand. Specifically, we present the infrared predissociation spectroscopy of mass-selected $[\mathrm{MOH}]^{+}\left(\mathrm{H}_{2} \mathrm{O}\right)_{1-4}$ clusters, with $\mathrm{M}=\mathrm{Mn}, \mathrm{Fe}, \mathrm{Co}, \mathrm{Ni}, \mathrm{Cu}$, and $\mathrm{Zn}$. The experimental spectra are analyzed with the help of density functional theory calculations. The vibrations in the $\mathrm{OH}$ stretch region, between $2600 \mathrm{~cm}^{-1}$ and $3800 \mathrm{~cm}^{-1}$, are used to reveal the coordination number and solvation structure of these clusters. Particularly, several hydration motifs are found for these transition metal clusters, with their relative energies dependent on the metalhydroxide interaction. We also find a progression of hydroxide frequency behavior as a function of solvation, which is related to the modulation of the vibrational Stark shift. The results point to the water molecules acting as a polarizable medium that affects the charge-transfer interaction even in the molecular solvation regime.

\section{Experimental and computational details}

The vibrational predissociation spectra of $\mathrm{D}_{2}$-tagged $[\mathrm{MOH}]^{+}$$\left(\mathrm{H}_{2} \mathrm{O}\right)_{n}(\mathrm{M}=\mathrm{Mn}-\mathrm{Zn})$ complexes were acquired using a homebuilt cryogenic ion photofragment spectrometer, described in detail previously. ${ }^{6}$ Ions of interest were generated via electrospray ionization of $\sim 1 \mathrm{mM}$ aqueous solution of the corresponding metal sulfate, guided by hexapole ion guides through three differentially pumped stages, and collected in a 3D quadrupole ion trap (Jordan TOF) held at $10 \mathrm{~K}$. Buffer gas, consisting of $10 \% \mathrm{D}_{2}$ in a balance of helium, was pulsed into the ion trap for collisional cooling and formation of $\mathrm{D}_{2}$ adducts, which serve as messengers for vibrational predissociation spectroscopy. After a $90 \mathrm{~ms}$ delay allowing for the evacuation of the buffer gas, the cooled ions were extracted from the trap into a time-of-flight mass spectrometer. The species corresponding to the $m / z$ of the $[\mathrm{MOH}]^{+}\left(\mathrm{H}_{2} \mathrm{O}\right)_{n} \cdot \mathrm{D}_{2}$ ions were isolated using a mass gate and intersected with the output of a Nd:YAG pumped tunable OPO/OPA laser system (Laservision). When the IR photon energy is resonant with a vibrational transition, the absorption of a single photon is sufficient to induce the evaporation of the weakly bound $\mathrm{D}_{2}$ tag. Photofragment ions corresponding to the bare $[\mathrm{MOH}]^{+}\left(\mathrm{H}_{2} \mathrm{O}\right)_{n}$ species were then separated from the parent ions in a two-stage reflectron. The resulting photofragment intensity as a function of the photon energy yielded linear IR spectra. The final intensities of the experimental spectra were normalized to the laser output power.

To aid the analysis of the experimental spectra, electronic structure calculations were performed using the Gaussian 09 computational package. ${ }^{27}$ Geometry optimizations, with Gaussian 09 standard tight convergence criteria, and harmonic frequency calculations were carried out at the cam-B3LYP/def2TZVP level of theory. Previous works ${ }^{7,28}$ have shown that the cam-B3LYP functional yields reasonable binding energies and more importantly, harmonic vibrational spectra (scaled by a factor of 0.955 ) that showed good agreement with experiment for $[\mathrm{MOH}]^{+}\left(\mathrm{H}_{2} \mathrm{O}\right)_{n}$. Charge analysis on the metal and hydroxide were carried out using natural population analysis of NBO $6 .^{29}$ Lastly, isomer searches were guided by chemical intuition. Various binding sites for each additional water molecule were explored with geometry optimization carried out at normal convergence criteria. Similar structures were eliminated before tight convergence was applied.

\section{Results and analysis}

The vibrational spectra of $[\mathrm{MOH}]^{+}\left(\mathrm{H}_{2} \mathrm{O}\right)_{n}$, with $\mathrm{M}=\mathrm{Mn}, \mathrm{Fe}, \mathrm{Co}$, $\mathrm{Ni}, \mathrm{Cu}, \mathrm{Zn}$, are shown in Fig. 1-6. For all the metal species studied here, most of the vibrational features are in the 3600$3800 \mathrm{~cm}^{-1}$ free $\mathrm{OH}$ region. For the larger $n=4$ clusters, all metal species show additional features between 2500-3500 $\mathrm{cm}^{-1}$, characteristic of hydrogen-bonded (H-bonded) $\mathrm{OH}$ vibrations. All the experimental peak positions and assignments are summarized in Table 1 . The ground states of the $[\mathrm{MOH}]^{+}\left(\mathrm{H}_{2} \mathrm{O}\right)_{n}$ species have the same spin multiplicity as the bare $\mathrm{M}^{2+}$ ion. This yields sextet for $\mathrm{Mn}$, quintet for $\mathrm{Fe}$, quartet for $\mathrm{Co}$, triplet for $\mathrm{Ni}$, doublet for $\mathrm{Cu}$, and singlet for $\mathrm{Zn}$.

The experimental vibrational spectra of the singly hydrated clusters and the $[\mathrm{CuOH}]^{+}\left(\mathrm{H}_{2} \mathrm{O}\right)_{1-3}$ clusters have been analyzed in detail previously. ${ }^{6,7}$ The data are reproduced here for comparison. The assignment process here is similar to that carried out in the previous studies, where the harmonic vibrational spectra calculated at the cam-B3LYP/def2TZVP level serve as the main guidance. The cam-B3LYP functional yielded harmonic vibrational spectra with good agreement with experimental spectra, except for two previously ${ }^{6}$ noted systematic deviations. First, the hydroxide stretch frequency, which is extremely sensitive to the charge transfer between the metal center and the hydroxide, is typically overestimated by $\sim 10-30 \mathrm{~cm}^{-1}$. Second, the strength of the $\mathrm{D}_{2}-\mathrm{H}_{2} \mathrm{O}$ interaction is overestimated, resulting in an overly redshifted symmetric stretch for the $\mathrm{D}_{2}$ tagged water. This error may arise from anharmonic nature of this weak interaction, ${ }^{30}$ which is not captured by our harmonic calculations. As discussed in detail in our earlier report on $\mathrm{CuOH}^{+}\left(\mathrm{H}_{2} \mathrm{O}\right)_{n}$ clusters, ${ }^{6}$ higher level $a b$ initio calculations, such as CCSD, can provide a better description of the $\mathrm{D}_{2}-\mathrm{H}_{2} \mathrm{O}$ interaction, but the hydroxide frequency is worse. While error in $\mathrm{D}_{2}-\mathrm{H}_{2} \mathrm{O}$ interaction only affects that specific water, the error in hydroxide frequency reflects improper treatment of the charge transfer which is likely to affect the whole cluster. For this reason, we rely on the cam-B3LYP calculated 
harmonic spectra. To simplify the figures and the discussion, only the assigned isomers and their calculated spectra are shown here. Additional isomers and their calculated spectra for the $n=4$ clusters are shown in ESI. $\dagger$

Finally, for the calculated spectra presented here, the $\mathrm{D}_{2}$ tag is not included once it binds on the water. In our previous study of the $[\mathrm{CuOH}]^{+}$system, it was found that the $\mathrm{D}_{2}$ tag binds to the metal center for the smaller clusters and moves onto one of the water molecules when the coordination sphere of the metal is filled. This can be deduced from the experimental spectra by looking at the frequency of the weak (nominally forbidden) $\mathrm{D}_{2}$ stretch. Namely, $\mathrm{D}_{2}$ interacting directly with the metal center has a frequency lower than $2900 \mathrm{~cm}^{-1}$ while $\mathrm{D}_{2}$ interacting with a water has a frequency around $2960 \mathrm{~cm}^{-1}$. Additionally, the $\mathrm{D}_{2}$-perturbed water has a symmetric stretch in the 3580 $3600 \mathrm{~cm}^{-1}$ region, $\sim 30 \mathrm{~cm}^{-1}$ redshifted from the unperturbed symmetric stretch. The exclusion of $\mathrm{D}_{2}$ in the larger cluster calculations is mainly due to the aforementioned error in the $\mathrm{D}_{2}-\mathrm{H}_{2} \mathrm{O}$ interaction. The calculated IR spectra including the $\mathrm{D}_{2}$ tag typically show greater deviations from experimental spectra than the bare cluster, and therefore do not add any useful information for making assignments. Examples of these calculated results are shown in the ESI $\dagger$ for further considerations. Note that when comparing calculated spectrum of the bare cluster to the experimental spectrum, the most noticeable differences are the lack of $\mathrm{D}_{2}$ stretch and an additional $\mathrm{H}_{2} \mathrm{O}$ stretch in the $3580-3600 \mathrm{~cm}^{-1}$ region.

\section{(a) $[\mathrm{MnOH}]^{+}\left(\mathrm{H}_{2} \mathbf{O}\right)_{n}$}

The experimental IR predissociation spectra of $[\mathrm{MnOH}]^{+}\left(\mathrm{H}_{2} \mathrm{O}\right)_{1-4}$ with corresponding calculated spectra and geometries are shown in Fig. 1. The experimental spectrum of the singly hydrated species has three bands in the $\mathrm{OH}$ stretch region corresponding to the $\mathrm{H}_{2} \mathrm{O}$ symmetric $\left(\mathrm{H}_{2} \mathrm{O}-\mathrm{s}\right)$ and antisymmetric $\left(\mathrm{H}_{2} \mathrm{O}\right.$-as $)$ stretch and the hydroxide $(\mathrm{OH})$ stretch. These three bands remain well-separated up to the $n=3$ cluster. Note that the additional features around $3700 \mathrm{~cm}^{-1}$ in the $n=1$ spectrum is due to coupling of the $\mathrm{H}_{2} \mathrm{O}$-as stretch with hindered internal rotation. . $^{74,26}$

The $n=2$ cluster has the two water molecules and hydroxide arranged in a quasi-planar $\mathrm{T}$ geometry with a weak $\mathrm{HO}-\mathrm{H}_{2} \mathrm{O}$ interaction. This gives rise to a doublet for the $\mathrm{H}_{2} \mathrm{O}$-s and $\mathrm{H}_{2} \mathrm{O}$-as modes. The bare $n=3$ cluster has a distorted tetrahedral geometry with two weak $\mathrm{HO}-\mathrm{H}_{2} \mathrm{O}$ interactions, again giving rise to $\mathrm{H}_{2} \mathrm{O}$-S and $\mathrm{H}_{2} \mathrm{O}$-as doublets. The feature at $3597 \mathrm{~cm}^{-1}$ is assigned to $\mathrm{D}_{2}$ perturbed $\mathrm{H}_{2} \mathrm{O}-\mathrm{s}$ while the feature at $3568 \mathrm{~cm}^{-1}$ is assigned to $\mathrm{H}_{2} \mathrm{O}$-s with $\mathrm{HO}-\mathrm{H}_{2} \mathrm{O}$ interaction. The effect of $\mathrm{D}_{2}$ tag addition on this spectrum is further analyzed in ESI. $\dagger$ The experimental spectrum of the $n=4$ cluster shows two broad and redshifted $\mathrm{H}$-bonding features centered around $2650 \mathrm{~cm}^{-1}$ and $3150 \mathrm{~cm}^{-1}$, indicating that the metal coordination shell is closed at $n=3$. The two lowest energy isomers, in which the fourth water is interacting directly with the hydroxide moiety, are found to be present in the experimental spectrum. The first isomer has a four-membered H-bond ring, with the secondshell water accepting an H-bond from a water and donating an

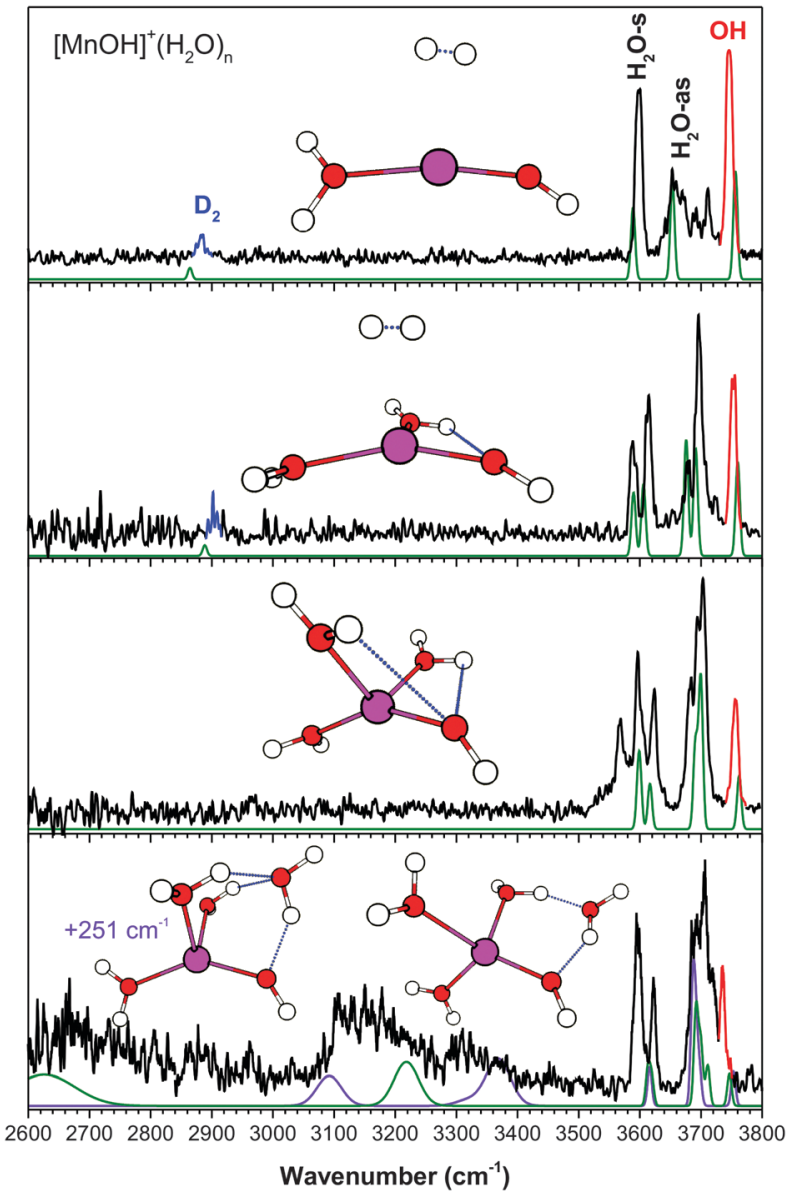

Fig. 1 The experimental (black) and calculated (purple/green, cam-B3LYP/ def2TZVP) vibrational spectra of $[\mathrm{MnOH}]^{+}\left(\mathrm{H}_{2} \mathrm{O}\right)_{n} \cdot \mathrm{D}_{2}$. Highlighted in red is the hydroxide stretch and in blue is the $\mathrm{D}_{2}$ stretch.

$\mathrm{H}$-bond to the hydroxide (AD configuration). This geometry gives rise to the very broad feature at $\sim 2650 \mathrm{~cm}^{-1}$ corresponding to the $\mathrm{H}_{2} \mathrm{O}-\mathrm{H}_{2} \mathrm{O} \mathrm{H}$-bond, and a feature at $\sim 3150 \mathrm{~cm}^{-1}$ corresponding to the $\mathrm{HO}-\mathrm{H}_{2} \mathrm{O}$ interaction. The other isomer, $251 \mathrm{~cm}^{-1}$ higher in energy, has the second-shell water in a double acceptor-single donor (AAD) configuration. Its presence is responsible for the very broad and asymmetric appearance of the $\sim 3150 \mathrm{~cm}^{-1}$ feature. Notably, the broad shoulder at $\sim 3300 \mathrm{~cm}^{-1}$ is likely due to this isomer, corresponding to the two $\mathrm{H}_{2} \mathrm{O}-\mathrm{H}_{2} \mathrm{O} \mathrm{H}$-bonds. In the $\sim 3600 \mathrm{~cm}^{-1}$ region, the calculated $\mathrm{H}_{2} \mathrm{O}$-s of the free water molecules for both isomers have the same frequency, and it agrees well with the experimental feature at $3623 \mathrm{~cm}^{-1}$. The $3597 \mathrm{~cm}^{-1}$ feature is therefore assigned to $\mathrm{H}_{2} \mathrm{O}-\mathrm{s}$ of the $\mathrm{D}_{2}$ tagged water. The $\sim 3700 \mathrm{~cm}^{-1}$ region of the experimental spectrum has several partially resolved peaks, which correspond to the $\mathrm{H}_{2} \mathrm{O}$-as stretch of water (or the non $\mathrm{H}$-bonded $\mathrm{OH}$ of a water). Lastly, calculations also yielded similar hydroxide stretch frequencies for both isomers, and the bluest experimental feature at $3735 \mathrm{~cm}^{-1}$ is assigned to this vibration.

\section{(b) $[\mathrm{FeOH}]^{+}\left(\mathrm{H}_{2} \mathrm{O}\right)_{n}$}

Fig. 2 shows the experimental IR spectra and calculated results for $[\mathrm{FeOH}]^{+}\left(\mathrm{H}_{2} \mathrm{O}\right)_{1-4}$. Similar to $[\mathrm{MnOH}]^{+}$, the $[\mathrm{FeOH}]^{+}$series has 


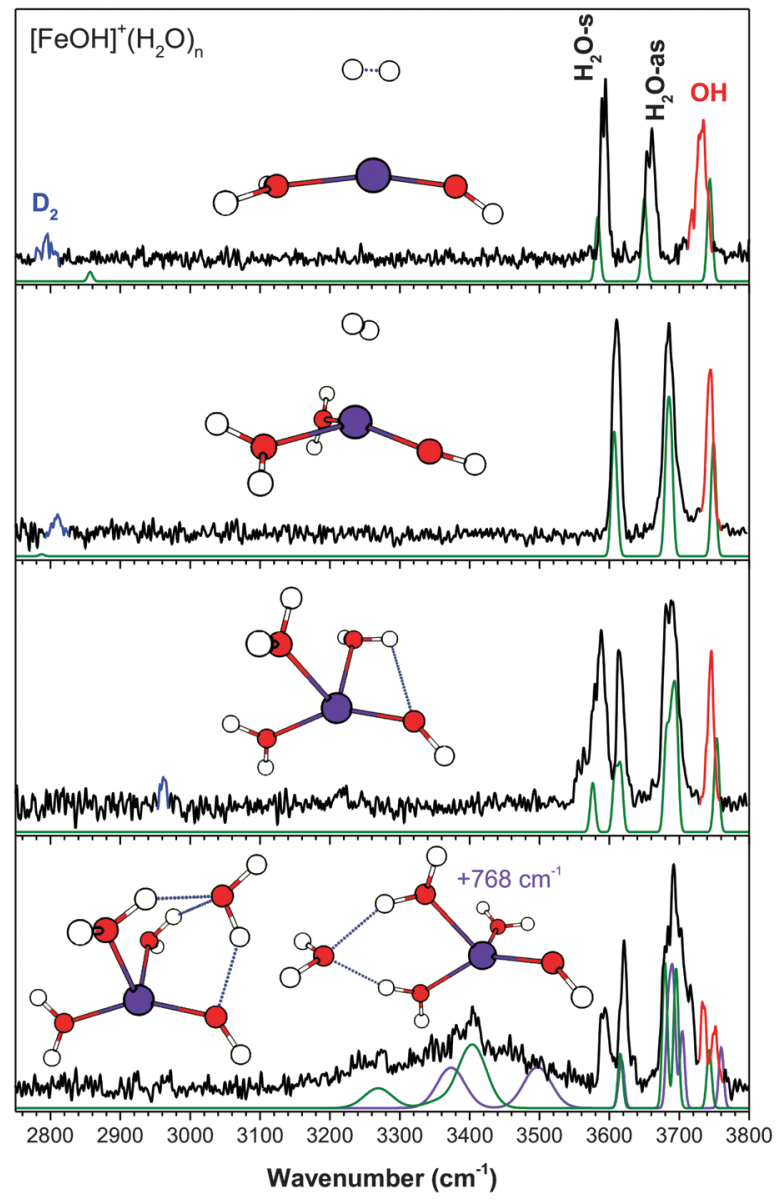

Fig. 2 The experimental (black) and calculated (purple/green, at cam$\mathrm{B} 3 \mathrm{LYP} /$ def2TZVP) vibrational spectra of $[\mathrm{FeOH}]^{+}\left(\mathrm{H}_{2} \mathrm{O}\right)_{n} \cdot \mathrm{D}_{2}$. Highlighted in red is the hydroxide stretch and in blue is the $D_{2}$ stretch.

three distinct bands in the $\mathrm{OH}$ stretch region corresponding to the $\mathrm{H}_{2} \mathrm{O}$-s, the $\mathrm{H}_{2} \mathrm{O}$-as, and the hydroxide stretch. With increasing solvation, the $\mathrm{H}_{2} \mathrm{O}$-as band and hydroxide stretch move towards each other, but they do not yet overlap in the $n=4$ spectrum.

The calculated spectrum of the lowest energy isomer of the $n=2$ cluster shows excellent agreement with the experimental spectrum. The water molecules and hydroxide are arranged in a distorted trigonal planar geometry, with the two water molecules essentially equivalent. This results in a simple spectrum with three narrow features slightly blueshifted from those in the $n=1$ spectrum. The bare $n=3$ cluster is tetrahedral in shape with one weak $\mathrm{HO}-\mathrm{H}_{2} \mathrm{O}$ interaction. The appearance of the spectrum is very similar to that of $[\mathrm{MnOH}]^{+}\left(\mathrm{H}_{2} \mathrm{O}\right)_{3}$, and the assignments are similar as well, with the $\mathrm{D}_{2}$ tag moving onto a water ligand and giving rise to the additional feature at $3586 \mathrm{~cm}^{-1}$.

The experimental spectrum of the $n=4$ cluster shows contributions from at least two isomers. This is indicated primarily by the two distinct features in the hydroxide stretch region around $3740 \mathrm{~cm}^{-1}$. The lowest energy isomer has an AAD water interacting directly with the hydroxide. Its calculated spectrum accounts for part of the intensity in the $3200-3500 \mathrm{~cm}^{-1}$ region, as well as the $3734 \mathrm{~cm}^{-1}$ hydroxide peak. The second isomer, $768 \mathrm{~cm}^{-1}$ higher in energy, has the second shell water in an AA configuration accepting two H-bonds from the water ligands opposite the hydroxide. The hydroxide moiety here only has a weak interaction with a nearby water, resulting in the higher frequency $3751 \mathrm{~cm}^{-1}$ feature. No other isomers within $\sim 1000 \mathrm{~cm}^{-1}$ can account for this peak. This isomer also has two calculated transitions at 3373 and $3497 \mathrm{~cm}^{-1}$ which result in the very broad appearance of the feature at $\sim 3400 \mathrm{~cm}^{-1}$. The relative intensity of the two hydroxide features indicates an almost equal presence of both isomers, despite the large calculated energy difference. The lack of any intensity around $\sim 2600 \mathrm{~cm}^{-1}$ indicates that the isomer with an $\mathrm{AD}$ second shell water (lowest energy isomer in $\left.[\mathrm{MnOH}]^{+}\left(\mathrm{H}_{2} \mathrm{O}\right)_{4}\right)$ is not present here, even though it is calculated to only be $257 \mathrm{~cm}^{-1}$ higher in energy than the AAD isomer. It should be noted that the errors in the calculated energetics appear to be larger for the Fe species compared to the other metal species studied here. Lastly, although all the experimentally observed intensities can be accounted for by the two isomers discussed above (the $3593 \mathrm{~cm}^{-1}$ feature correspond to the $\mathrm{D}_{2}$ perturbed $\mathrm{H}_{2} \mathrm{O}-\mathrm{s}$ ), minor contributions from an additional isomer, with all four water molecules in the first shell, cannot be eliminated. Further discussions are presented in ESI. $\dagger$

\section{(c) $[\mathrm{CoOH}]^{+}\left(\mathrm{H}_{2} \mathrm{O}\right)_{n}$}

The experimental and calculated IR spectra of $[\mathrm{CoOH}]^{+}\left(\mathrm{H}_{2} \mathrm{O}\right)_{1-4}$ are shown in Fig. 3. Even for the smallest cluster, the hydroxide stretch is only partially resolved from the $\mathrm{H}_{2} \mathrm{O}$-as band, and they are completely overlapped for the larger clusters. The assigned geometry of the $n=2$ cluster, a distorted trigonal planar structure with two nearly equivalent water molecules, is similar to that of $[\mathrm{FeOH}]^{+}$. This gives rise to a very simple experimental spectrum, where the $3611 \mathrm{~cm}^{-1}$ feature is assigned to the $\mathrm{H}_{2} \mathrm{O}-\mathrm{s}$ stretch and the slightly broader $3686 \mathrm{~cm}^{-1}$ feature is assigned to the hydroxide and $\mathrm{H}_{2} \mathrm{O}$-as stretch. This isomer is $100 \mathrm{~cm}^{-1}$ higher in energy than the isomer with a planar $\mathrm{T}$ structure, which involves a slight $\mathrm{HO}-\mathrm{H}_{2} \mathrm{O}$ interaction. Such an interaction would result in a splitting of each water peak, clearly not present in the experimental spectrum. The higher signal-tonoise ratio of the $n=2$ spectrum also reveals several small features in the $2900-3300 \mathrm{~cm}^{-1}$ region which are not reproduced in the calculations. Similar features are observed occasionally in the other experimental spectra presented here, and are likely due to combination/overtone bands. Notably, the feature at $3250 \mathrm{~cm}^{-1}$ is likely the overtone of the $\mathrm{H}_{2} \mathrm{O}$ bend vibration. Small features are also visible above $3720 \mathrm{~cm}^{-1}$, likely due to combination bands of the water stretch and low frequency libration modes. ${ }^{31}$ The $n=3$ cluster has a distorted tetrahedral geometry, similar to that of the $[\mathrm{MnOH}]^{+}$and $[\mathrm{FeOH}]^{+}$species. One of the water molecules interacts with hydroxide, resulting in the $3545 \mathrm{~cm}^{-1}$ feature. The $3586 \mathrm{~cm}^{-1}$ feature is assigned to the $\mathrm{D}_{2}$-tagged $\mathrm{H}_{2} \mathrm{O}$-s, while the $3619 \mathrm{~cm}^{-1}$ feature is the unperturbed $\mathrm{H}_{2} \mathrm{O}$-s. The partially resolved doublet at $3673 \mathrm{~cm}^{-1}$ and $3700 \mathrm{~cm}^{-1}$ is assigned to the $\mathrm{H}_{2} \mathrm{O}$-as stretches and the overlapping hydroxide stretch. 


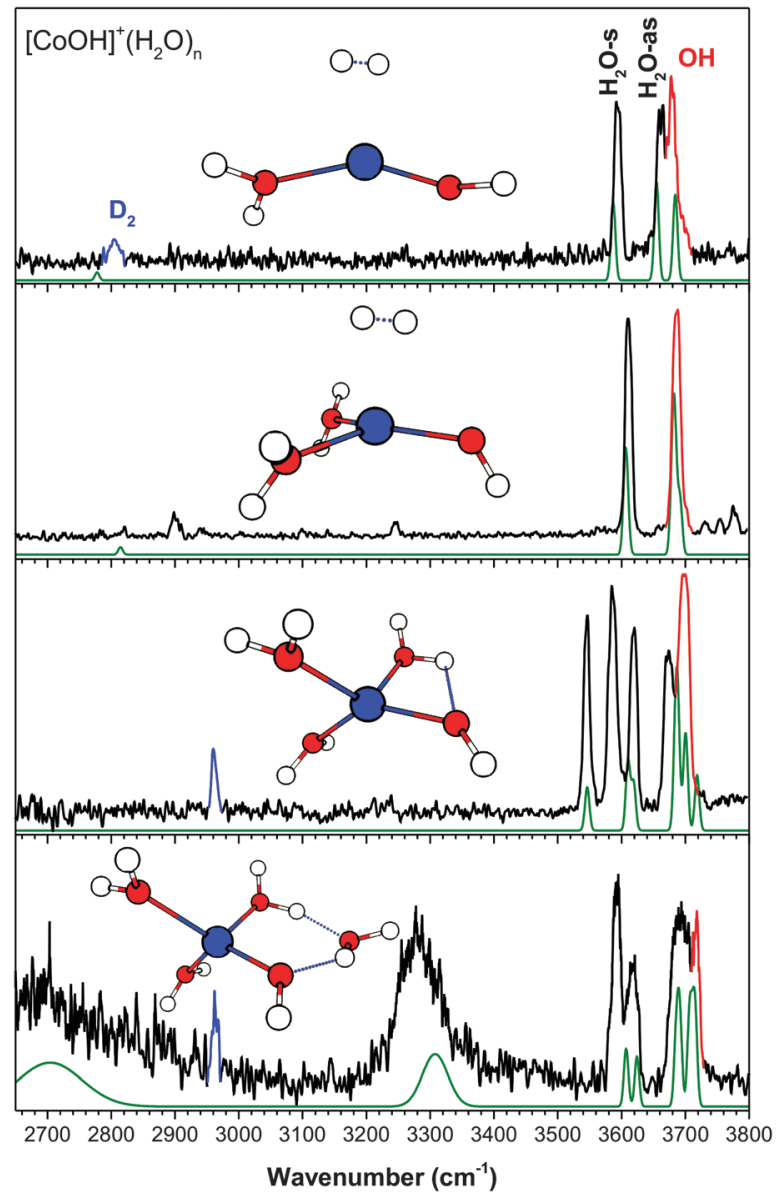

Fig. 3 The experimental (black) and calculated (green, at cam-B3LYP/ def2TZVP) vibrational spectra of $[\mathrm{CoOH}]^{+}\left(\mathrm{H}_{2} \mathrm{O}\right)_{n} \cdot \mathrm{D}_{2}$. Highlighted in red is the hydroxide stretch and in blue is the $\mathrm{D}_{2}$ stretch.

The coordination shell closes at $n=3$ for $[\mathrm{CoOH}]^{+}$as well. The calculated spectrum of the lowest energy isomer of the $n=4$ cluster shows an excellent agreement with the experiment, accounting for all the observed spectral features. The geometry of this isomer has the second shell water in an $\mathrm{AD}$ configuration, forming an $\mathrm{H}$-bond ring with the hydroxide moiety. The $\mathrm{H}_{2} \mathrm{O}-\mathrm{H}_{2} \mathrm{O}$ H-bond accounts for the broad $2650 \mathrm{~cm}^{-1}$ feature, and the $\mathrm{HO}-\mathrm{H}_{2} \mathrm{O}$ H-bond accounts for the $3280 \mathrm{~cm}^{-1}$ feature. The hydroxide stretch is assigned to the higher frequency side of the broad partially resolved $\mathrm{H}_{2} \mathrm{O}$-as band. Isomers with the second shell water in an AAD or AA configuration similar to those of $[\mathrm{FeOH}]^{+}\left(\mathrm{H}_{2} \mathrm{O}\right)_{4}$ are calculated to be $555 \mathrm{~cm}^{-1}$ and $573 \mathrm{~cm}^{-1}$ higher in energy. They both have calculated intensities in the $3400-3500 \mathrm{~cm}^{-1}$ region, and therefore do not have significant presence in the experimental spectrum.

\section{(d) $[\mathrm{NiOH}]^{+}\left(\mathrm{H}_{2} \mathrm{O}\right)_{n}$}

Fig. 4 shows the experimental and calculated IR spectra for the $n=1-5$ clusters of $[\mathrm{NiOH}]^{+}\left(\mathrm{H}_{2} \mathrm{O}\right)_{n}$. Similar to the $[\mathrm{CoOH}]^{+}$ species, the hydroxide stretch of $[\mathrm{NiOH}]^{+}$is overlapped with the $\mathrm{H}_{2} \mathrm{O}$-as band, giving rise to only two bands centered at $\sim 3600 \mathrm{~cm}^{-1}$ and $\sim 3700 \mathrm{~cm}^{-1}$ for the $n=1$ species. However, there is an

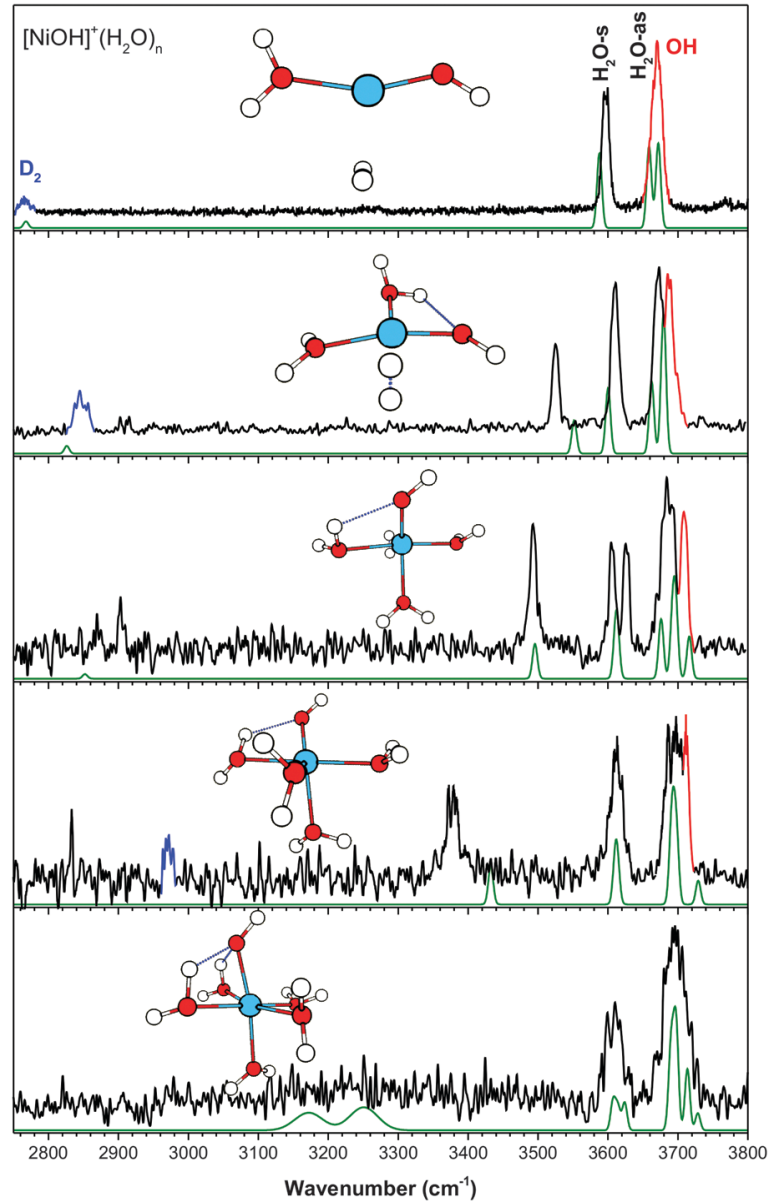

Fig. 4 The experimental (black) and calculated (green, at cam-B3LYP/ def2TZVP) vibrational spectra of $[\mathrm{NiOH}]^{+}\left(\mathrm{H}_{2} \mathrm{O}\right)_{n} \cdot \mathrm{D}_{2}$. Highlighted in red is the hydroxide stretch and in blue is the $\mathrm{D}_{2}$ stretch.

additional distinct isolated feature which progressively redshifts with increasing solvation. Furthermore, even in the spectrum of the larger $n=5$ cluster, there are no very intense redshifted features, clearly making the solvation of $[\mathrm{NiOH}]^{+}$ different than the other metal species presented thus far.

In the $n=2$ cluster, the water molecules and hydroxide are in a T-shaped planar geometry. The $\sim 90^{\circ}$ angle between the water and the hydroxide results in a stronger $\mathrm{HO}-\mathrm{H}_{2} \mathrm{O}$ interaction, giving rise to the redshifted feature at $3525 \mathrm{~cm}^{-1}$. The calculation cannot fully capture this interaction, but the other spectral features have good agreement with the experiment. This isomer is calculated to be $126 \mathrm{~cm}^{-1}$ higher in energy than the lowest energy structure found, which has $\mathrm{D}_{2}$ on an axial location similar to that of $[\mathrm{MnOH}]^{+},[\mathrm{FeOH}]^{+}$, and $[\mathrm{CoOH}]^{+}$. That geometry, however, does not have an $\mathrm{HO}-\mathrm{H}_{2} \mathrm{O}$ interaction and cannot account for the $3525 \mathrm{~cm}^{-1}$ experimental feature. In the $n=3$ cluster, the water replaces the $\mathrm{D}_{2}$ in the equatorial position, and the additional repulsion results in a yet stronger $\mathrm{HO}-\mathrm{H}_{2} \mathrm{O}$ interaction and a redshifted peak at $3493 \mathrm{~cm}^{-1}$. Here, the calculation shows a good overall agreement with the experiment, but the doublet at $3606 / 3626 \mathrm{~cm}^{-1}$ is calculated to have the same frequency. The increasing $\mathrm{HO}-\mathrm{H}_{2} \mathrm{O}$ interaction trend 
continues in the $n=4$ cluster, with the fourth water still interacting with the $\mathrm{Ni}$ center. We note that the strong $\mathrm{HO}-\mathrm{H}_{2} \mathrm{O}$ interaction in the $n=4$ cluster gives rise to a vibrational feature at $3378 \mathrm{~cm}^{-1}$, which is of similar frequency as that of the $\mathrm{H}$-bonded water stretch due to second shell formation for the other metal species. However, the $[\mathrm{NiOH}]^{+}$feature has comparably narrow width and low intensity in the experimental spectrum, pointing to the difference in its H-bond. The calculated geometry for the $n=5$ cluster has an octahedral arrangement, with all six ligands in the first solvation shell. The structure has two water molecules strongly interacting with the hydroxide, with calculated frequencies of $3172 \mathrm{~cm}^{-1}$ and $3251 \mathrm{~cm}^{-1}$. Interestingly, these redshifted features suddenly broaden out in the $n=5$ cluster, such that they almost disappear into the baseline. This is similar to the spectra of the $n=4$ and 5 clusters of $[\mathrm{MgOH}]^{+}\left(\mathrm{H}_{2} \mathrm{O}\right)_{n}$ and $[\mathrm{CaOH}]^{+}\left(\mathrm{H}_{2} \mathrm{O}\right)_{n}{ }^{5}$ Note that for the alkali earth species, the extremely broad feature spanning $>500 \mathrm{~cm}^{-1}$ arises from a similar $\mathrm{HO}-\mathrm{H}_{2} \mathrm{O}$ interaction arranged in an octahedral geometry. Isomers with the fifth water in the second shell are all calculated to be $\sim 1000 \mathrm{~cm}^{-1}$ higher in energy, with significant intensities in the $2500-3400 \mathrm{~cm}^{-1}$ region. Due to insufficient ion signal, the spectrum of $[\mathrm{NiOH}]^{+}\left(\mathrm{H}_{2} \mathrm{O}\right)_{6}$ cluster could not be collected. This drop in intensity in the mass spectrum from $n=5$ to $n=6$ suggests the completion of the first coordination shell at $n=5$.

\section{(e) $[\mathrm{CuOH}]^{+}\left(\mathrm{H}_{2} \mathrm{O}\right)_{n}$}

The assignment and analysis of the solvated $[\mathrm{CuOH}]^{+}$clusters have been previously published by us for $n=1-3,{ }^{6}$ and by Sweeney et al. ${ }^{32}$ for $n=2-9$. Recent improvements allowed us to acquire a better signal-to-noise spectrum for the $n=3$ cluster and a vibrational spectrum for the $n=4$ cluster. Fig. 5 shows the entire $n=1-4$ series. In contrast to the metal species discussed so far, the hydroxide stretch in the singly hydrated $[\mathrm{CuOH}]^{+}$lies below the $\mathrm{H}_{2} \mathrm{O}$-s and blueshifts to overlap with the $\mathrm{H}_{2} \mathrm{O}$-as in the $n=3$ and 4 clusters. Furthermore, the $\mathrm{D}_{2}$ tag is already on the water ligand for $n=2$ and gives rise to a comparably complex spectrum. Here, the $\mathrm{D}_{2}$ interaction yields a doublet feature for both $\mathrm{H}_{2} \mathrm{O}$-s and $\mathrm{H}_{2} \mathrm{O}$-as stretch, and is responsible for the differences between the calculated and experimental spectra. The most stable isomer of the $n=3$ cluster has a nearly square planar geometry and is the dominant species contributing to the experimental spectrum. The enhanced signal-tonoise spectrum for $n=3$ now clearly shows an additional $\mathrm{H}$-bonded feature at $3370 \mathrm{~cm}^{-1}$, indicating the presence of a second isomer as pointed out by Sweeney et $a l^{32}$ This isomer, calculated to be $432 \mathrm{~cm}^{-1}$ higher in energy here, has the third water in the second shell bonded to two water ligands in an AA configuration, yielding the distinctive $\mathrm{H}$-bond feature.

The calculated spectrum of the lowest energy isomer for the $n=4$ cluster agrees well with the experimental spectrum. This is also the lowest energy isomer found by Sweeney et al. ${ }^{32}$ This isomer, also planar, has three water molecules in the primary metal coordination shell and the fourth water in an AA configuration between two water ligands. It is an extension of both $n=3$ isomers. The double $\mathrm{H}$-bond interaction gives rise to the

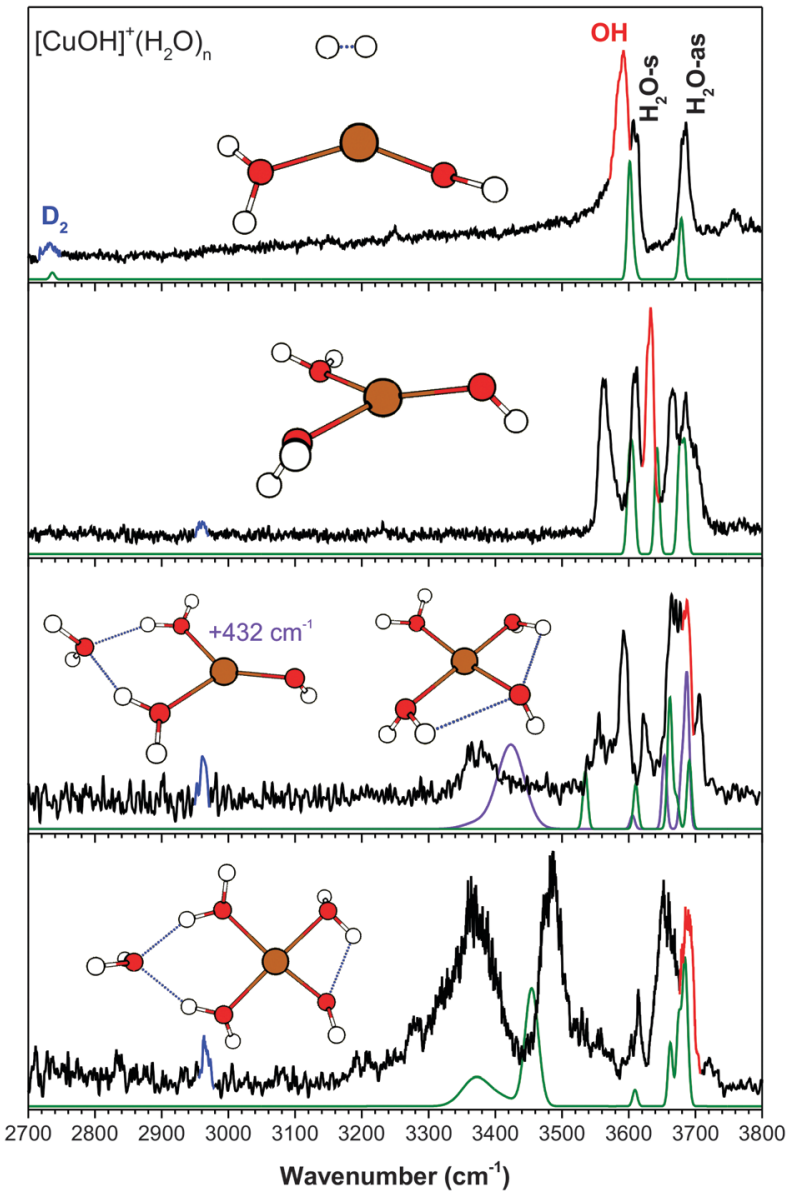

Fig. 5 The experimental (black) and calculated (green, at cam-B3LYP/ def2TZVP) vibrational spectra of $[\mathrm{CuOH}]^{+}\left(\mathrm{H}_{2} \mathrm{O}\right)_{n} \cdot \mathrm{D}_{2}$. Highlighted in red is the hydroxide stretch and in blue is the $\mathrm{D}_{2}$ stretch.

two intense features observed at $3370 \mathrm{~cm}^{-1}$ and $3485 \mathrm{~cm}^{-1}$. Calculations also indicate that the hydroxide stretch is now the highest frequency vibration, overlapped with several $\mathrm{H}_{2} \mathrm{O}$-as vibrations, and they are all assigned to the partially resolved $3690 \mathrm{~cm}^{-1}$ feature. The other low energy isomers reported by Sweeney et $a .^{32}$ have calculated intensities below $3200 \mathrm{~cm}^{-1}$ and do not appear to contribute to the experimental spectrum observed here.

\section{(f) $[\mathrm{ZnOH}]^{+}\left(\mathrm{H}_{2} \mathrm{O}\right)_{n}$}

Fig. 6 shows the experimental and calculated results for $[\mathrm{ZnOH}]^{+}\left(\mathrm{H}_{2} \mathrm{O}\right)_{1-4}$. As pointed out for the singly hydrated species, ${ }^{7}$ the calculated results for $[\mathrm{ZnOH}]^{+}$has a slightly larger error $\left(\sim 20-30 \mathrm{~cm}^{-1}\right)$ for the hydroxide stretch frequency compared to the other metal species. This is true for the larger clusters as well. Furthermore, similar to the $[\mathrm{MnOH}]^{+}$species, the $\mathrm{H}_{2} \mathrm{O}$-as feature in $[\mathrm{ZnOH}]^{+} n=1$ is complicated by coupling of this stretch with hindered internal rotation. The $n=2$ cluster has a planar $\mathrm{T}$ geometry with the two water molecules nearly equivalent. The calculated spectrum of the bare cluster does not show a good agreement with the experiment. Notably, both the $\mathrm{H}_{2} \mathrm{O}-\mathrm{s}$ and $\mathrm{H}_{2} \mathrm{O}$-as features are split into a doublet, which is similar to the 


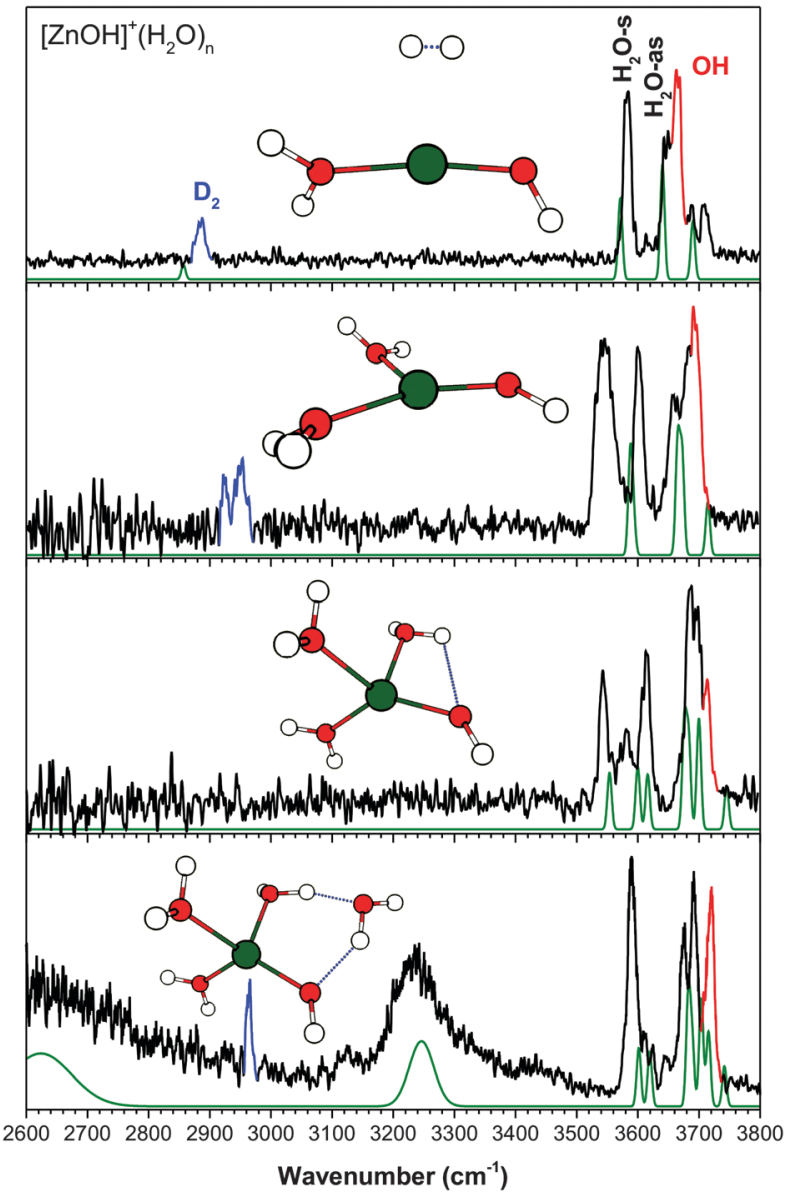

Fig. 6 The experimental (black) and calculated (green, at cam-B3LYP/ def2TZVP) vibrational spectra of $[\mathrm{ZnOH}]^{+}\left(\mathrm{H}_{2} \mathrm{O}\right)_{n} \cdot \mathrm{D}_{2}$. Highlighted in red is the hydroxide stretch and in blue is the $\mathrm{D}_{2}$ stretch. corresponding $[\mathrm{CuOH}]^{+}$cluster. This points to the $\mathrm{D}_{2}$ tag residing on a water ligand, and the broad $\sim 2950 \mathrm{~cm}^{-1} \mathrm{D}_{2}$ stretch feature further indicate that there may be more than one tag isomer. Specifically, the $3602 \mathrm{~cm}^{-1}$ feature is assigned to the free $\mathrm{H}_{2} \mathrm{O}-\mathrm{s}$, which, similar to the $n=1$ cluster, is slightly blueshifted from the calculated frequency. The broader and asymmetric feature at $3545 \mathrm{~cm}^{-1}$ is then assigned to the $\mathrm{D}_{2}$ perturbed $\mathrm{H}_{2} \mathrm{O}$-s. The $\mathrm{H}_{2} \mathrm{O}$-as stretch is also perturbed by the $\mathrm{D}_{2}$ tag, similar to $[\mathrm{CuOH}]^{+}\left(\mathrm{H}_{2} \mathrm{O}\right)_{2}$, giving rise to the partially resolved band at $3650-3700 \mathrm{~cm}^{-1}$. The highest frequency side of this band is assigned to the hydroxide stretch.

The experimental spectrum of the $n=3$ cluster is similar in appearance to the corresponding $[\mathrm{MnOH}]^{+},[\mathrm{FeOH}]^{+}$, and $[\mathrm{CoOH}]^{+}$ species, in agreement with its calculated geometry being a quasitetrahedral structure. The $\mathrm{HO}-\mathrm{H}_{2} \mathrm{O}$ interaction here gives rise to the feature at $3543 \mathrm{~cm}^{-1}$. The peak at $3580 \mathrm{~cm}^{-1}$ is assigned to the $\mathrm{D}_{2}$ tagged water stretch and the $3614 \mathrm{~cm}^{-1}$ feature is assigned to the free $\mathrm{H}_{2} \mathrm{O}$-s. The $\mathrm{H}_{2} \mathrm{O}$-as features are again only partially resolved from each other and the $3714 \mathrm{~cm}^{-1}$ hydroxide stretch. Similar to the other tetrahedral species, the $\mathrm{Zn}$ coordination shell is complete at $n=3$, and the spectrum of the $n=4$ cluster has broad and intense features at $\sim 2600 \mathrm{~cm}^{-1}$ and $\sim 3230 \mathrm{~cm}^{-1}$. The lowest energy isomer for $n=4$ has the second shell water in an $\mathrm{AD}$ configuration between a water and the hydroxide. This isomer has two redshifted features in excellent agreement with the experimental features, and it accounts for most of the intensities in the $3600-3800 \mathrm{~cm}^{-1}$ region as well. Minor presence of an additional isomer, with the second shell water in an AAD configuration, cannot be ruled out. See ESI $\dagger$ for additional details.

\section{Discussion}

\section{(a) Coordination and solvation structure}

The assigned vibrational spectra allow us to take a closer look at the different trends in the coordination geometry and

Table 1 Experimental frequencies and assignments of the $[\mathrm{MOH}]^{+}\left(\mathrm{H}_{2} \mathrm{O}\right)_{2-4}$ clusters. The subscript denotes the group to which the $\mathrm{H}$-bond is donated

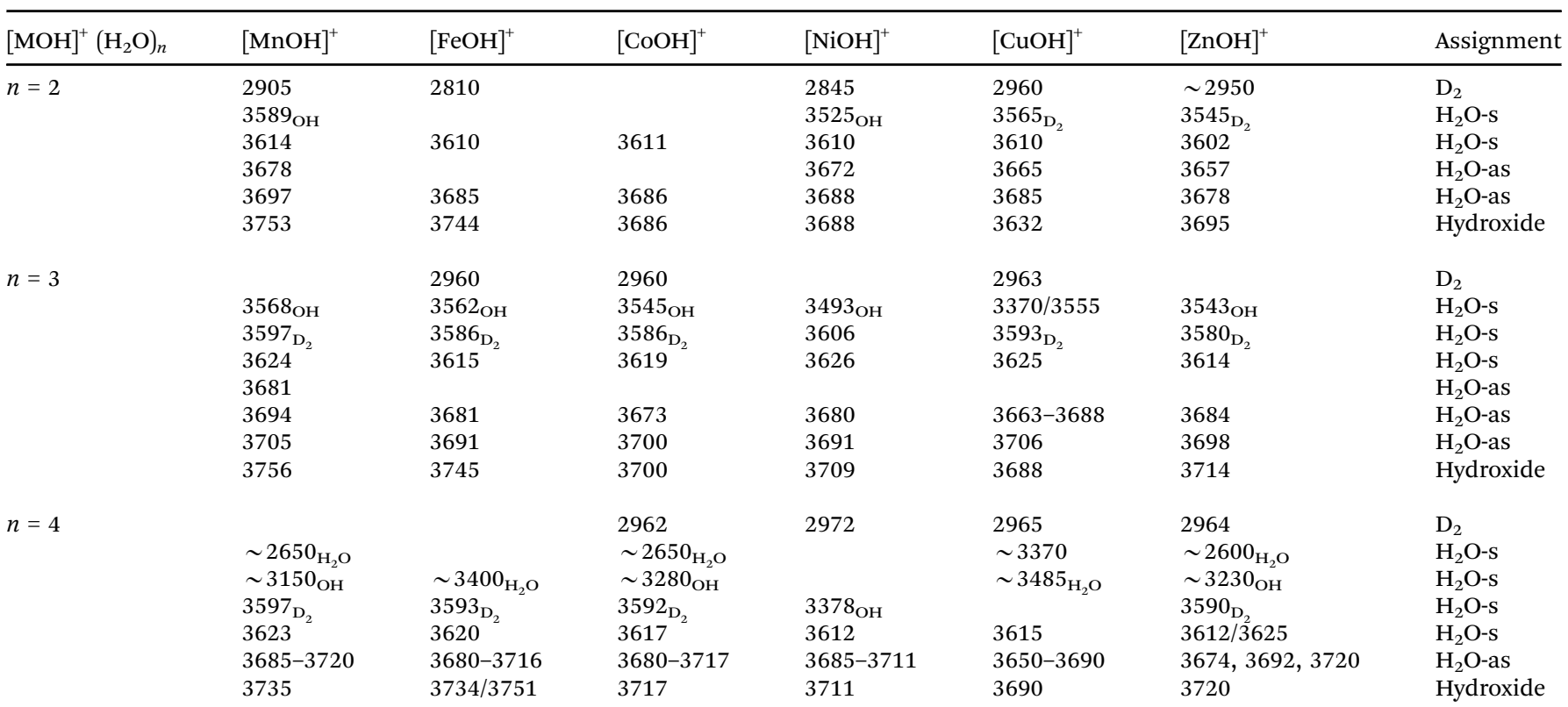




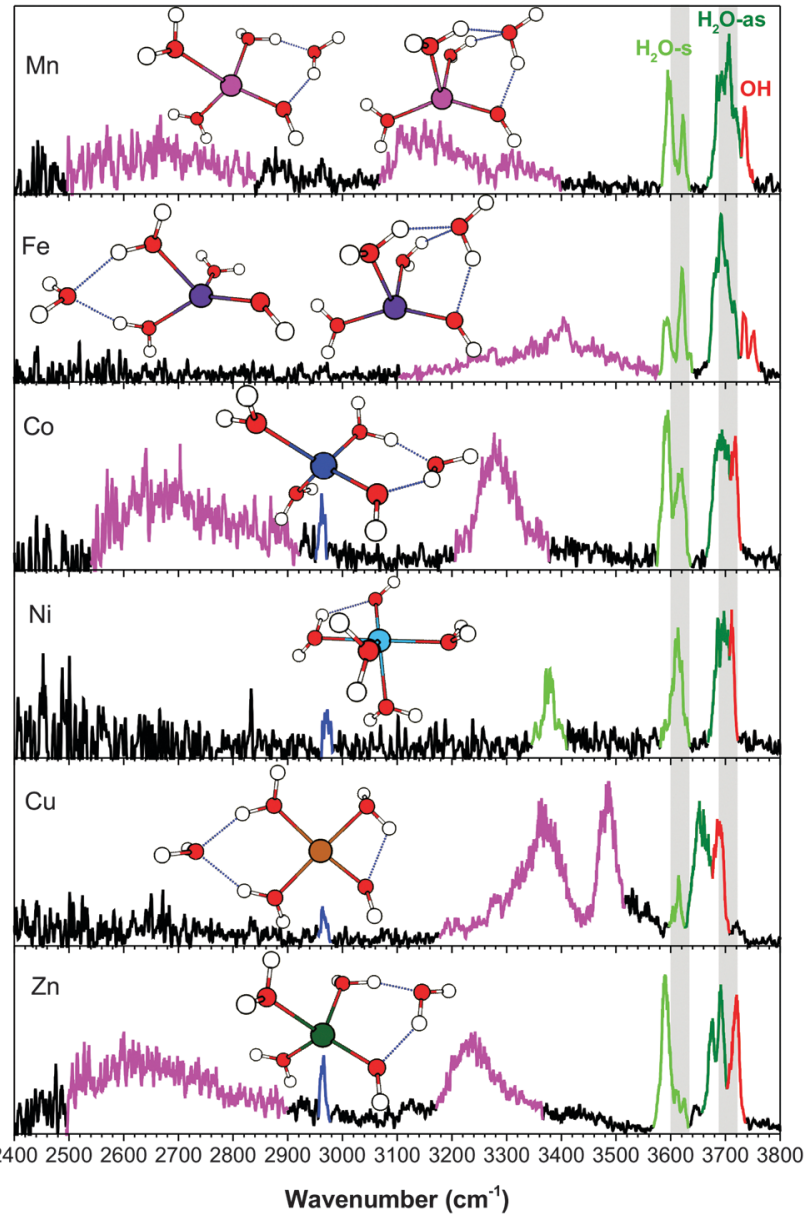

Fig. 7 The experimental spectra of $[\mathrm{MOH}]^{+}\left(\mathrm{H}_{2} \mathrm{O}\right)_{4} \cdot \mathrm{D}_{2}$ complexes in the $2400-3800 \mathrm{~cm}^{-1}$ region. Highlighted in blue is the $D_{2}$ stretch, in green are the $\mathrm{H}_{2} \mathrm{O}$-s and $\mathrm{H}_{2} \mathrm{O}$-as stretches, in red is the hydroxide stretch, and in magenta are the $\mathrm{H}$-bonded $\mathrm{OH}$ stretches involving the second shell water. The grey bars allow for comparison of the $\mathrm{H}_{2} \mathrm{O}$-s and $\mathrm{H}_{2} \mathrm{O}$-as bands for different metals (highlighting the higher frequency edge of the bands).

solvation structure. To aid the discussions, we present the experimental spectra and calculated structures of the $[\mathrm{MOH}]^{+}\left(\mathrm{H}_{2} \mathrm{O}\right)_{2-4}$ clusters grouped by solvation (i.e. $n=2,3$, and 4) in Fig. S8, S9 (ESI $\dagger$ ) and Fig. 7.

For the $n=2$ clusters (Fig. S8, ESI $\dagger$ ), all the metal species have a relatively similar trigonal structure. Specifically, the two water molecules in the $[\mathrm{FeOH}]^{+}$and $[\mathrm{CoOH}]^{+}$clusters are both free and have the same vibrational frequencies. In the $[\mathrm{MnOH}]^{+}$ and $[\mathrm{NiOH}]^{+}$clusters, one of the water molecules has a weak interaction with the hydroxide, leading to a splitting in the $\mathrm{H}_{2} \mathrm{O}$-s and $\mathrm{H}_{2} \mathrm{O}$-as modes. In $[\mathrm{CuOH}]^{+}$and $[\mathrm{ZnOH}]^{+}$, the water modes are split due to the presence of the $\mathrm{D}_{2}$ tag on a water, and these features are correspondingly broader and more asymmetrical.

The IR spectra of the $n=3$ clusters (Fig. S9, ESI $\dagger$ ) highlight the different coordination behaviors of the various metal species. The $[\mathrm{MnOH}]^{+},[\mathrm{FeOH}]^{+},[\mathrm{CoOH}]^{+}$, and $[\mathrm{ZnOH}]^{+}$clusters all have a distorted tetrahedral geometry and the proximity of the ligands leads to one water weakly interacting with the hydroxide.
This interaction gives rise to a feature in the $3540-3570 \mathrm{~cm}^{-1}$ region. On the other hand, both the $[\mathrm{NiOH}]^{+}$and the dominant $[\mathrm{CuOH}]^{+}$isomer have a quasi-square-planar geometry. With this structure, the $[\mathrm{NiOH}]^{+}$cluster has the strongest $\mathrm{HO}-\mathrm{H}_{2} \mathrm{O}$ interaction, with a redshifted frequency of $3493 \mathrm{~cm}^{-1}$. The minor isomer of $[\mathrm{CuOH}]^{+}$yields the first $\mathrm{H}$-bonded $\mathrm{OH}$ stretch for this series of $[\mathrm{MOH}]^{+}$clusters. For all the species except $\mathrm{Ni}$, the $\mathrm{D}_{2}$ tag now resides on a water, and a feature $\sim 30 \mathrm{~cm}^{-1}$ redshifted from the free $\mathrm{H}_{2} \mathrm{O}-\mathrm{s}$ is observed in the experimental spectra.

The vibrational spectra of the $n=4$ clusters, in the broader $2400-3800 \mathrm{~cm}^{-1}$ region, are shown in Fig. 7. Unlike the smaller clusters, there is now significant activity in the H-bonding region. $[\mathrm{NiOH}]^{+}$is the unique species here, with the fourth water residing in the first solvation shell. The proximity of the ligands in the octahedral coordination leads to a redshifted feature at $3378 \mathrm{~cm}^{-1}$, resulting from the $\mathrm{HO}-\mathrm{H}_{2} \mathrm{O}$ interaction. This frequency indicates that the interaction is almost as strong as some $\mathrm{H}_{2} \mathrm{O}-\mathrm{H}_{2} \mathrm{O}$ interactions in the other metal species, though it remains a rather narrow feature with relatively low intensity. For all the other $[\mathrm{MOH}]^{+}\left(\mathrm{H}_{2} \mathrm{O}\right)_{4}$ clusters, the fourth water resides in the second shell, giving rise to characteristic broad and intense redshifted H-bonded features. The experimental spectra point to two distinct binding sites for the second shell water. First, the $[\mathrm{MnOH}]^{+},[\mathrm{CoOH}]^{+}$, and $[\mathrm{ZnOH}]^{+}$ spectra all have a very broad feature spanning $2500-2900 \mathrm{~cm}^{-1}$, which is absent in the $[\mathrm{FeOH}]^{+}$and $[\mathrm{CuOH}]^{+}$spectra. Calculations show that this feature is due to the second shell water in an $\mathrm{AD}$ configuration, forming a ring between a water and the hydroxide. The $\mathrm{H}_{2} \mathrm{O}-\mathrm{H}_{2} \mathrm{O} \mathrm{H}$-bond in this ring is very strong, giving rise to this low frequency feature. The corresponding $\mathrm{HO}-\mathrm{H}_{2} \mathrm{O} \mathrm{H}$-bond yields the $\sim 3200 \mathrm{~cm}^{-1}$ feature. A related motif in which the second shell water is in an AAD configuration between two water molecules and the hydroxide is found for one of the $[\mathrm{FeOH}]^{+}$and $[\mathrm{MnOH}]^{+}$isomers. This configuration has the all the $\mathrm{H}$-bonded features in the $3100-3400 \mathrm{~cm}^{-1}$ region. The weaker $\mathrm{H}_{2} \mathrm{O}-\mathrm{H}_{2} \mathrm{O}$ interaction here is due to the distribution of the interaction over two equivalent $\mathrm{H}$-bonds. We note that the $\mathrm{HO}-\mathrm{H}_{2} \mathrm{O}$ interaction here creates a motif in which simple proton transfer to the adjacent oxygen would effectively transfer the location of the hydroxide in the first coordination sphere. The other distinct location for the second shell water is at the opposite side of the cluster, in an AA configuration between two water ligands. This H-bond is of a more typical water-water interaction, and gives rise to features in the 3300$3500 \mathrm{~cm}^{-1}$ region for $[\mathrm{CuOH}]^{+}$and one of the $[\mathrm{FeOH}]^{+}$isomers.

The position and binding motif of the second shell water reveals the relative strength of the $\mathrm{H}_{2} \mathrm{O}-\mathrm{H}_{2} \mathrm{O}$ and $\mathrm{HO}-\mathrm{H}_{2} \mathrm{O}$ interactions for the different metal species. As discussed for the singly hydrated species, ${ }^{7}$ electron transfer from the hydroxide to the metal center varies as a function of the 2nd ionization energy of the metal. This makes $[\mathrm{CuOH}]^{+}$the species with the largest charge transfer and therefore the smallest residual charge on the hydroxide (see Table 2). With less charge on the hydroxide, the $\mathrm{HO}-\mathrm{H}_{2} \mathrm{O}$ interaction becomes less energetically favorable and the second shell water preferably binds in an AA configuration between two water ligands. The $[\mathrm{MnOH}]^{+}$, 
Table 2 The calculated (cam-B3LYP/def2TZVP) metal (M) NPA charge, hydroxide (OH) NPA charge, and M-OH bond length for the optimized geometries shown in Fig. 1-6. For species where multiple isomers are present in the experimental spectrum, the dominant species is listed. In the case of $n=4$ cluster for $\mathrm{FeOH}$, the AAD isomer is listed

\begin{tabular}{|c|c|c|c|c|c|c|c|c|c|c|c|c|}
\hline \multirow[b]{2}{*}[\mathrm{MOH}]{$^{+}\left(\mathrm{H}_{2} \mathrm{O}\right)_{n}$} & \multicolumn{3}{|l|}{$n=1$} & \multicolumn{3}{|l|}{$n=2$} & \multicolumn{3}{|l|}{$n=3$} & \multicolumn{3}{|l|}{$n=4$} \\
\hline & $\mathrm{M}(\mathrm{e})$ & $\mathrm{OH}(\mathrm{e})$ & M-OH $(\AA)$ & $\mathrm{M}(\mathrm{e})$ & $\mathrm{OH}(\mathrm{e})$ & M-OH $(\AA)$ & $\mathbf{M}(\mathrm{e})$ & $\mathrm{OH}(\mathrm{e})$ & M-OH $(\AA)$ & $\mathbf{M}(\mathrm{e})$ & $\mathrm{OH}(\mathrm{e})$ & M-OH $(\AA)$ \\
\hline$[\mathrm{MgOH}]^{+}$ & 1.84 & -0.90 & 1.723 & 1.83 & -0.91 & 1.740 & 1.82 & -0.91 & 1.789 & 1.81 & -0.89 & 1.833 \\
\hline$[\mathrm{CaOH}]^{+}$ & 1.84 & -0.86 & 1.930 & 1.83 & -0.87 & 1.958 & 1.85 & -0.90 & 2.016 & 1.86 & -0.89 & 2.139 \\
\hline$[\mathrm{MnOH}]^{+}$ & 1.54 & -0.64 & 1.758 & 1.55 & -0.70 & 1.804 & 1.58 & -0.74 & 1.836 & 1.61 & -0.76 & 1.878 \\
\hline$[\mathrm{FeOH}]^{+}$ & 1.46 & -0.58 & 1.717 & 1.45 & -0.62 & 1.755 & 1.50 & -0.67 & 1.778 & 1.52 & -0.70 & 1.818 \\
\hline$[\mathrm{CoOH}]^{+}$ & 1.41 & -0.55 & 1.723 & 1.42 & -0.62 & 1.761 & 1.49 & -0.68 & 1.787 & 1.52 & -0.71 & 1.816 \\
\hline$[\mathrm{NiOH}]^{+}$ & 1.31 & -0.47 & 1.695 & 1.36 & -0.57 & 1.752 & 1.42 & -0.67 & 1.791 & 1.47 & -0.71 & 1.808 \\
\hline$[\mathrm{CuOH}]^{+}$ & 1.20 & -0.32 & 1.754 & 1.29 & -0.43 & 1.741 & 1.40 & -0.64 & 1.811 & 1.42 & -0.67 & 1.814 \\
\hline$[\mathrm{ZnOH}]^{+}$ & 1.61 & -0.72 & 1.740 & 1.65 & -0.76 & 1.758 & 1.69 & -0.81 & 1.794 & 1.71 & -0.82 & 1.823 \\
\hline
\end{tabular}

$[\mathrm{FeOH}]^{+},[\mathrm{CoOH}]^{+}$and $[\mathrm{ZnOH}]^{+}$species have larger $(\geq 0.7 e)$ NPA charge on the hydroxide ligand, which favors the interaction of the second shell water with the hydroxide. $[\mathrm{FeOH}]^{+}$is different than the other species because it has the AAD motif as a dominant configuration. This can be explained by the geometry of the first coordination shell. The distorted tetrahedral geometry of $[\mathrm{FeOH}]^{+}$has the smallest $\mathrm{H}_{2} \mathrm{O}-\mathrm{M}-\mathrm{H}_{2} \mathrm{O}$ angle in the $n=3$ cluster, at about $85^{\circ}$. This favors the AAD interaction, which has a smaller $\mathrm{H}_{2} \mathrm{O}-\mathrm{M}-\mathrm{H}_{2} \mathrm{O}$ angle than the AD motif. Furthermore, the absence of the $\mathrm{AD}$ isomer and the strong presence of the $\mathrm{AA}$ isomer suggest that the charge on hydroxide is also a factor here, especially considering that $[\mathrm{FeOH}]^{+}$has the second lowest calculated NPA charge on its hydroxide. Similarly, structural considerations may also play a part in the relative stability of the $[\mathrm{CuOH}]^{+}$ isomers, where the square planar structure is more strained when accommodating the second shell water in an $\mathrm{AD}$ configuration. Altogether, it appears that the solvation structures of $[\mathrm{MOH}]^{+}$are influenced by a combination of charge transfer and coordination geometry.

The coordination behavior of the $[\mathrm{MOH}]^{+}$complexes can also be compared to that of the corresponding $\mathrm{M}^{+}\left(\mathrm{H}_{2} \mathrm{O}\right)_{n}$ and $\mathrm{M}^{2+}\left(\mathrm{H}_{2} \mathrm{O}\right)_{n}$ complexes, summarized in Table 3. Previous studies of $\mathrm{M}^{2+}\left(\mathrm{H}_{2} \mathrm{O}\right)_{n}$ clusters by Williams and coworkers ${ }^{22,23,33}$ show that the average coordination numbers $(\mathrm{CNs})$ of $\mathrm{Mn}^{2+}$, $\mathrm{Fe}^{2+}, \mathrm{Co}^{2+}$, and $\mathrm{Ni}^{2+}$ ions complexed with water are all approximately 6. $\mathrm{Cu}^{2+}$ and $\mathrm{Zn}^{2+}$ complexes were found to have $\mathrm{CN}=4$ and $\mathrm{CN}=5$, respectively. Studies of $\mathrm{M}^{+}\left(\mathrm{H}_{2} \mathrm{O}\right)_{n}$ complexes $^{18,19,24}$ showed that $\mathrm{Co}^{+}$and $\mathrm{Zn}^{+}$complexes have $\mathrm{CN}=3$ while $\mathrm{Ni}^{+}$has $\mathrm{CN}=3$ or $4 .^{20} \mathrm{Fe}^{+}$and $\mathrm{Cu}^{+}$clusters both have $\mathrm{CN}=2$ predominantly, with $\mathrm{Fe}^{+}\left(\mathrm{H}_{2} \mathrm{O}\right)_{n}$ possibly having 4 coordinate geometries as well. ${ }^{17,21}$ The $[\mathrm{MOH}]^{+}$species, on the other hand, seem to have CNs somewhere in between the two extremes. Namely, $[\mathrm{MnOH}]^{+},[\mathrm{FeOH}]^{+},[\mathrm{CoOH}]^{+}$, and $[\mathrm{ZnOH}]^{+}$ have $\mathrm{CN}=4$, which is larger than that of the $\mathrm{M}^{+}\left(\mathrm{H}_{2} \mathrm{O}\right)_{n}$ clusters but smaller than that of the known $\mathrm{M}^{2+}\left(\mathrm{H}_{2} \mathrm{O}\right)_{n}$ clusters. Interestingly, $[\mathrm{CuOH}]^{+}$and $[\mathrm{NiOH}]^{+}$have the same coordination numbers as the corresponding $\mathrm{M}^{2+}$ ions despite having the lower NPA charge on the metal center. This indicates that neither the formal charge nor NPA charge are sufficient to predict the coordination environment around the metal center, especially when a charged ligand is located in the coordination sphere.
Table 3 Coordination numbers of $\mathrm{M}^{+}, \mathrm{M}^{2+}$, and $[\mathrm{MOH}]^{+}$complexes with water molecules

\begin{tabular}{llll}
\hline $\mathrm{M}$ & $\mathrm{M}^{+}$ & $\mathrm{M}^{2+}$ & {$[\mathrm{MOH}]^{+}$} \\
\hline $\mathrm{Mn}$ & - & 6 (ref. 23) & 4 \\
$\mathrm{Fe}$ & 2 or 4 (ref. 17) & 6 (ref. 23) & 4 \\
$\mathrm{Co}$ & 3 (ref. 18) & 6 (ref. 23) & 4 \\
$\mathrm{Ni}$ & 3 or 4 (ref. 20) & 6 (ref. 23) & 6 \\
$\mathrm{Cu}$ & 2 (ref. 21) & 4 (ref. 22) & 3 or 4 \\
$\mathrm{Zn}$ & 3 (ref. 19) & 5 or 6 (ref. 33) & 4
\end{tabular}

\section{(b) Hydroxide frequency}

In our previous study on the $[\mathrm{MOH}]^{+}\left(\mathrm{H}_{2} \mathrm{O}\right)$ species, we found that the frequency of the hydroxide stretch has a strong dependence on the metal species. ${ }^{7}$ This was attributed to the vibrational Stark shift ${ }^{3-42}$ induced by the charged metal center, with charge transfer between the metal ion and the hydroxide ligand being the most important factor in two ways. First, electron transfer from the hydroxide to the metal center reduces the magnitude of the electric field. Second, depletion of the excess electron on the hydroxide reduces the Stark tuning rate, because, unlike the hydroxide anion, the hydroxyl radical frequency is almost insensitive to electric field. Overall the hydroxide frequency was found to be linearly proportional to $q_{\mathrm{OH}} q_{\mathrm{M}} / R^{2}$ where $q_{\mathrm{OH}}$ and $q_{\mathrm{M}}$ are the charge on the hydroxide and the metal, respectively, and $R$ is the distance between the metal and the center of the hydroxide $\mathrm{O}-\mathrm{H}$ bond.

Here we can look at the effect of solvation on this trend, which is summarized in Fig. 8. The top panel shows that the metal dependence of the hydroxide frequency observed for the $n=1$ species continues for the larger clusters. However, the range of the hydroxide frequency narrows significantly with each additional water molecule, and it converges toward $\sim 3700 \mathrm{~cm}^{-1}$ for all the metal species studied here. Even though the solvation occurs predominately around the metal, the hydroxide frequency shows a high sensitivity to the solvation environment for some species. Notably there is a progression of behavior from $[\mathrm{CuOH}]^{+}$to $[\mathrm{MgOH}]^{+}$. The hydroxide frequencies of $[\mathrm{CuOH}]^{+},[\mathrm{ZnOH}]^{+},[\mathrm{NiOH}]^{+}$and $[\mathrm{CoOH}]^{+}$all blueshift with increasing number of water. On the other hand, the hydroxide frequencies redshift in $[\mathrm{MgOH}]^{+}$and $[\mathrm{CaOH}]^{+}$with increasing solvation. ${ }^{5}$ Finally, hydroxide frequencies of $[\mathrm{FeOH}]^{+}$and $[\mathrm{MnOH}]^{+}$ remain fairly constant as a function of solvation. 

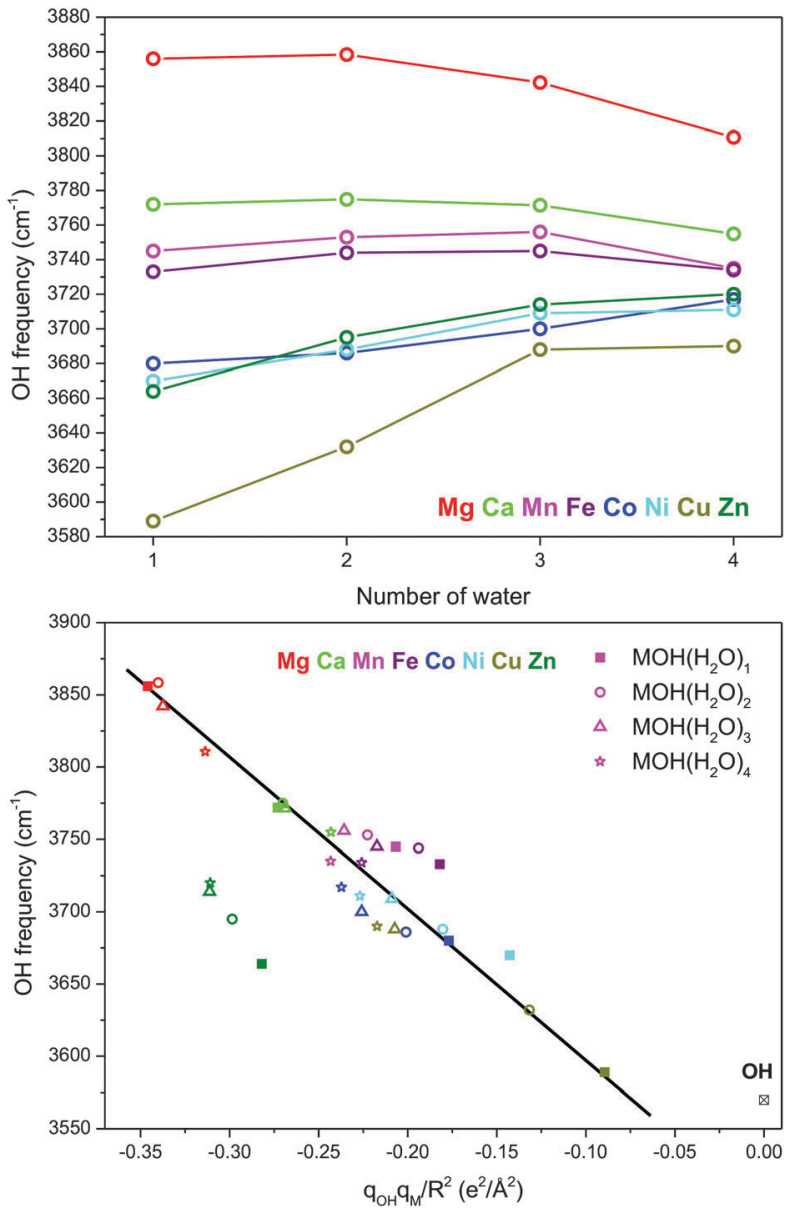

Fig. 8 Top panel: Experimental hydroxide frequency in $\mathrm{MOH}^{+}\left(\mathrm{H}_{2} \mathrm{O}\right)_{n}$ as a function of $n$. Bottom panel: Experimental hydroxide frequency as a function of $q_{\mathrm{OH}} q_{\mathrm{M}} / R^{2}$ where $q_{\mathrm{OH}}$ and $q_{\mathrm{M}}$ are the calculated charge on the hydroxide and the metal, respectively, and $R$ is the distance between the metal and the center of the $\mathrm{O}-\mathrm{H}$ bond. The data for $[\mathrm{MgOH}]^{+}$and $[\mathrm{CaOH}]^{+}$are from ref. 5. The straight line serves as a visual guidance.

We carried out a similar natural population analysis (NPA) for these larger solvation clusters as in our previous study. (Note: for species where multiple isomers are present in the experimental spectrum, the dominant species is considered. In the case of $[\mathrm{FeOH}]^{+}\left(\mathrm{H}_{2} \mathrm{O}\right)_{4}$, the AAD isomer is considered.) The localized charge on the metal center and the hydroxide moiety are listed in Table 2. The bottom panel of Fig. 8 shows the plot of the hydroxide frequency as a function of $q_{\mathrm{OH}} q_{\mathrm{M}} / R^{2}$, including the $[\mathrm{MgOH}]^{+}$and $[\mathrm{CaOH}]^{+}$species studied by Johnson et al. ${ }^{5}$ With the exception of $[\mathrm{ZnOH}]^{+}$, all the other species follow the linear $q_{\mathrm{OH}} q_{\mathrm{M}} / R^{2}$ relationship found for the $n=1$ clusters. The offset in the $[\mathrm{ZnOH}]^{+}$series is likely due to errors in the calculation of the $\mathrm{Zn}-\mathrm{OH}$ interaction and NPA charges as discussed previously for the singly solvated species. ${ }^{7}$ This is partly reflected in the discrepancy between calculated and experimental hydroxide frequencies as discussed in Section III-f. The more scattered appearance of the data points in the center of the plot is likely due to the inherent errors in the charge analysis as well as additional $\mathrm{HO}-\mathrm{H}_{2} \mathrm{O}$ interactions that affect the hydroxide stretch independent of the electric field.
Nonetheless, this graph shows that although the $[\mathrm{MgOH}]^{+}$and $[\mathrm{CuOH}]^{+}$species start at the opposite ends of the plot in the $n=1$ cluster, they both move toward the center with increasing number of water molecules. For the $n=4$ clusters, all the metal species except for $[\mathrm{MgOH}]^{+}$and $[\mathrm{ZnOH}]^{+}$are congregated around a $q_{\mathrm{OH}} q_{\mathrm{M}} / R^{2}$ of about $-0.22 \mathrm{e}^{2} \AA^{-2}$. This linear relationship indicates that modulation of the Stark shift is the primary reason behind the solvation dependent hydroxide frequency in these $[\mathrm{MOH}]^{+}$complexes, and provides an explanation for the opposing redshift/blueshift trends.

The reason for this behavior is twofold. First, as shown in Table 2, the magnitude of electron transfer between the hydroxide and the metal center is reduced with increasing solvation (i.e., the respective charges on the metal and hydroxide increases). This can be explained by dielectric charge stabilization from the water molecules surrounding the metal center. This effect is more pronounced for the species with larger charge transfer in the small clusters. For example, in $[\mathrm{CuOH}]^{+}$the charge on the metal goes from 1.20 in $n=1$ to 1.42 in $n=4$. This reduced charge transfer increases both the strength of the electric field and the Stark tuning rate of the hydroxide, leading to a blueshift of the hydroxide frequency. At the same time, a more crowded coordination around the metal center leads to a gradual lengthening of the $\mathrm{M}-\mathrm{OH}$ bond for all metal species considered here. The longer bond lengths lead to reduced electric field, and a redshift of the hydroxide frequency. This is the dominant effect for the already charge-separated species such as $[\mathrm{MgOH}]^{+}$and $[\mathrm{CaOH}]^{+}$. For the $[\mathrm{MnOH}]^{+}$and $[\mathrm{FeOH}]^{+}$ species, these two opposing trends effectively cancel out each other, resulting in a relatively constant hydroxide frequency as a function of solvation.

\section{Conclusion}

The vibrational spectra of $[\mathrm{MOH}]^{+}\left(\mathrm{H}_{2} \mathrm{O}\right)_{n} \cdot \mathrm{D}_{2}(\mathrm{M}=\mathrm{Mn}, \mathrm{Fe}, \mathrm{Co}$, $\mathrm{Ni}, \mathrm{Cu}$ and $\mathrm{Zn} ; n=2-4)$, acquired using cryogenic ion infrared predissociation spectroscopy are presented. The formation of the second coordination shell is observed for all the metals species except $[\mathrm{NiOH}]^{+}$. For $[\mathrm{MnOH}]^{+},[\mathrm{FeOH}]^{+},[\mathrm{CoOH}]^{+}$, and $[\mathrm{ZnOH}]^{+}$, the second shell begins with the addition of the fourth water. On the other hand, $[\mathrm{CuOH}]^{+}$can have either a 3-coordinate or a 4-coordinate first shell, with the 4-coordinate shell energetically favored for the $n=4$ cluster. $[\mathrm{NiOH}]^{+}$is found to have an octahedral geometry with the first shell likely closed at $n=5$. The different coordination numbers also correspond to different geometries, with $[\mathrm{CuOH}]^{+}$adopting a planar structure, $[\mathrm{NiOH}]^{+}$ adopting an octahedral structure, and the other species adopting a quasi-tetrahedral structure. For the second shell water, characteristic $\mathrm{H}$-bonded $\mathrm{OH}$ vibrations are observed in the 2500$3500 \mathrm{~cm}^{-1}$ region, pointing to different binding sites for different metal species. Specifically, the water molecule in the second shell can adopt either an $\mathrm{AD}$ or $\mathrm{AAD}$ configuration, interacting directly with the hydroxide moiety, or an AA configuration, interacting only with two water molecules. The relative energetics of different binding sites are found to be dictated by 
the first shell coordination geometry and the local charge present on the hydroxide. Finally, the hydroxide frequency exhibits very high sensitivity to metal species as well as solvation. Specifically, the $[\mathrm{ZnOH}]^{+},[\mathrm{CuOH}]^{+},[\mathrm{CoOH}]^{+}$and $[\mathrm{NiOH}]^{+}$clusters showed a blueshifting hydroxide stretch with increasing solvation whereas $[\mathrm{FeOH}]^{+}$and $[\mathrm{MnOH}]^{+}$clusters showed a fairly constant hydroxide stretch for $n=1-4$. The modulation of this frequency is dominated by the vibrational Stark shift observed for the $n=1$ clusters, despite the increasing and varying $\mathrm{H}$-bonding interactions around the hydroxide moiety.

\section{Acknowledgements}

This material is based upon work supported by the National Science Foundation under grant number CHE-1454086. The computational resources used in this work are supported by the National Science Foundation Grant CHE-0840494.

\section{References}

1 A. M. Ricks, A. D. Brathwaite and M. A. Duncan, J. Phys. Chem. A, 2013, 117, 11490-11498.

2 E. M. Duffy, B. M. Marsh and E. Garand, J. Phys. Chem. A, 2015, 119, 6326-6332.

3 R. J. Cooper, S. Heiles and E. R. Williams, Phys. Chem. Chem. Phys., 2015, 17, 15963-15975.

4 B. J. Knurr and J. M. Weber, J. Phys. Chem. A, 2015, 119, 843-850.

5 C. J. Johnson, L. C. Dzugan, A. B. Wolk, C. M. Leavitt, J. A. Fournier, A. B. McCoy and M. A. Johnson, J. Phys. Chem. A, 2014, 118, 7590-7597.

6 B. M. Marsh, J. Zhou and E. Garand, J. Phys. Chem. A, 2014, 118, 2063-2071.

7 B. M. Marsh, J. Zhou and E. Garand, Phys. Chem. Chem. Phys., 2015, DOI: 10.1039/c5cp01522g.

8 L. Jiang, T. Wende, R. Bergmann, G. Meijer and K. R. Asmis, J. Am. Chem. Soc., 2010, 132, 7398-7404.

9 N. F. Dalleska, K. Honma, L. S. Sunderlin and P. B. Armentrout, J. Am. Chem. Soc., 1994, 116, 3519-3528.

10 D. R. Carl, R. M. Moision and P. B. Armentrout, Int. J. Mass Spectrom., 2007, 265, 308-325.

11 D. R. Carl and P. B. Armentrout, J. Phys. Chem. A, 2012, 116, 3802-3815.

12 D. R. Carl and P. B. Armentrout, ChemPhysChem, 2013, 14, 681-697.

13 T. E. Cooper, D. R. Carl and P. B. Armentrout, J. Phys. Chem. A, 2009, 113, 13727-13741.

14 T. E. Hofstetter and P. B. Armentrout, J. Phys. Chem. A, 2013, 117, 1110-1123.

15 Y. Inokuchi, K. Ohshimo, F. Misaizu and N. Nishi, J. Phys. Chem. A, 2004, 108, 5034-5040.

16 M. F. Bush, J. T. O’Brien, J. S. Prell, C.-C. Wu, R. J. Saykally and E. R. Williams, J. Am. Chem. Soc., 2009, 131, 13270-13277.
17 K. Ohashi, J. Sasaki, G. Yamamoto, K. Judai, N. Nishi and H. Sekiya, J. Chem. Phys., 2014, 141, 214307.

18 K. Furukawa, K. Ohashi, N. Koga, T. Imamura, K. Judai, N. Nishi and H. Sekiya, Chem. Phys. Lett., 2011, 508, 202-206.

19 B. Bandyopadhyay, K. N. Reishus and M. A. Duncan, J. Phys. Chem. A, 2013, 117, 7794-7803.

20 R. S. Walters, E. D. Pillai and M. A. Duncan, J. Am. Chem. Soc., 2005, 127, 16599-16610.

21 T. Iino, K. Ohashi, Y. Mune, Y. Inokuchi, K. Judai, N. Nishi and H. Sekiya, Chem. Phys. Lett., 2006, 427, 24-28.

22 J. T. O'Brien and E. R. Williams, J. Phys. Chem. A, 2008, 112, 5893-5901.

23 J. T. O'Brien and E. R. Williams, J. Phys. Chem. A, 2011, 115, 14612-14619.

24 P. D. Carnegie, B. Bandyopadhyay and M. A. Duncan, J. Phys. Chem. A, 2011, 115, 7602-7609.

25 A. L. Nicely, D. J. Miller and J. M. Lisy, J. Mol. Spectrosc., 2009, 257, 157-163.

26 T. D. Vaden, B. Forinash and J. M. Lisy, J. Chem. Phys., 2002, 117, 4628-4631.

27 M. J. Frisch, G. W. Trucks, H. B. Schlegel, G. E. Scuseria, M. A. Robb, J. R. Cheeseman, G. Scalmani, V. Barone, B. Mennucci, G. A. Petersson, H. Nakatsuji, M. Caricato, X. Li, H. P. Hratchian, A. F. Izmaylov, J. Bloino, G. Zheng, J. L. Sonnenberg, M. Hada, M. Ehara, K. Toyota, R. Fukuda, J. Hasegawa, M. Ishida, T. Nakajima, Y. Honda, O. Kitao, H. Nakai, T. Vreven, J. A. Montgomery Jr., J. E. Peralta, F. Ogliaro, M. J. Bearpark, J. Heyd, E. N. Brothers, K. N. Kudin, V. N. Staroverov, R. Kobayashi, J. Normand, K. Raghavachari, A. P. Rendell, J. C. Burant, S. S. Iyengar, J. Tomasi, M. Cossi, N. Rega, N. J. Millam, M. Klene, J. E. Knox, J. B. Cross, V. Bakken, C. Adamo, J. Jaramillo, R. Gomperts, R. E. Stratmann, O. Yazyev, A. J. Austin, R. Cammi, C. Pomelli, J. W. Ochterski, R. L. Martin, K. Morokuma, V. G. Zakrzewski, G. A. Voth, P. Salvador, J. J. Dannenberg, S. Dapprich, A. D. Daniels, Ö. Farkas, J. B. Foresman, J. V. Ortiz, J. Cioslowski and D. J. Fox, Gaussian 09, Gaussian, Inc., Wallingford, CT, USA, 2009.

28 A. F. Sweeney and P. B. Armentrout, J. Phys. Chem. A, 2014, 118, 10210-10222.

29 E. D. Glendening, J. K. Badenhoop, A. E. Reed, J. E. Carpenter, J. A. Bohmann, C. M. Morales, C. R. Landis and F. Weinhold, NBO 6.0, Theoretical Chemistry Institute, University of Wisconsin-Madison, Madison, WI, USA, 2013.

30 M. Baer, D. Marx and G. Mathias, ChemPhysChem, 2011, 12, 1906-1915.

31 P. D. Carnegie, A. B. McCoy and M. A. Duncan, J. Phys. Chem. A, 2009, 113, 4849-4854.

32 A. F. Sweeney, J. T. O'Brien, E. R. Williams and P. B. Armentrout, Int. J. Mass Spectrom., 2015, 378, 270-280.

33 T. E. Cooper, J. T. O'Brien, E. R. Williams and P. B. Armentrout, J. Phys. Chem. A, 2010, 114, 12646-12655.

34 K. Hermansson, P. A. Bopp, D. Spångberg, L. Pejov, I. Bakó and P. D. Mitev, Chem. Phys. Lett., 2011, 514, 1-15.

35 K. Hermansson, Int. J. Quantum Chem., 1993, 45, 747-758. 
36 K. Hermansson, Chem. Phys., 1993, 170, 177-184.

37 S. S. Andrews and S. G. Boxer, J. Phys. Chem. A, 2000, 104, 11853-11863.

38 S. G. Boxer, J. Phys. Chem. B, 2009, 113, 2972-2983.

39 S. H. Brewer and S. Franzen, J. Chem. Phys., 2003, 119, 851-858.
40 T. Mani, D. C. Grills and J. R. Miller, J. Am. Chem. Soc., 2015, 137, 1136-1140.

41 J. T. O'Brien and E. R. Williams, J. Am. Chem. Soc., 2012, 134, 10228-10236.

42 J. S. Prell, J. T. O'Brien and E. R. Williams, J. Am. Chem. Soc., 2011, 133, 4810-4818. 